\title{
A Survey of Intercultural Adaptability for Foreign Students in Three Universities: Problems and Solutions*
}

\author{
Siqi Ye \\ College of Foreign Languages and Literatures, Chongqing Normal University, China \\ Haijiao Xue \\ College of Foreign Languages and Literatures, Chongqing Normal University, China \\ Yanling Zheng \\ College of Foreign Languages and Literatures, Chongqing Normal University, China
}

\begin{abstract}
This paper aims to explore the existing problems and solutions of foreign students' intercultural adaptability in three universities of university town in Chongqing from such aspects as campus cultural adaptation, material cultural adaptation, behavioral cultural adaption and Chinese traditional cultural adaption. By questionnaires, research group has found some major problems like, do not have an Chinese competence, unfamiliar with Chinese material culture, insensitive to Chongqing's behavioral culture, unfamiliar with Chinese traditional and local culture. After analyzing those possible reasons, this paper provides some solutions: implementing the same management of foreign students as Chinese students, strengthening social supports, strengthening the communication with foreign students and fostering foreign students' consciousness of Chinese traditional culture.
\end{abstract}

Index Terms - three universities, foreign students, intercultural adaption, problems and suggestions

\section{INTRODUCTION}

With the promotion of international influence, China links with other countries more closely, especially in higher educational field. Chongqing as the educational highland of the Southwestern China, plays an vital role in the Belt and Road Initiative and attracts a number of foreign students to study in Chongqing, China. Their intercultural adaptation problems caused by diverse cultural backgrounds are drawing much concern. Foreign students' intercultural adaptation refers to the process of psychological and behavioral changes that result from continuous contact between two different cultural groups, which contains psychological adaption and sociocultural adaption (Ward, 1991) or general adaption, work adaption, and interact adaption (Yang, 2009). As foreign students play an essential role in the international education, their intercultural adaptation becomes a hot issue in the whole international education process. As a consequence, many scholars are interested in exploring the issue from various perspectives, such as psychology, communication and comparative education, etc.. Lu (1990) finds that interpersonal communication is a common need of human beings, however, individuals in different cultural environments are culturally influenced by the choice of education and inherit a unique cultural gene. When they enter a new cultural environment, they find that the norms of interpersonal communication quite different from their own. Chen (2003) explores the intercultural adaptation factors of foreign students from the perspective of psychology, finding that external social culture, ecological environment and other factors have a significant impact on foreign students' internal psychological development. Yang (2009) finds that values and social supports have a great impact on foreign students from the perspective of communication. However, most of domestic intercultural researches have ignored some important cultural factors that affect intercultural adaptation, such as the traditions, the ideology, even the rules and regulations of a country. Cheng (2009) finds that culture contains material, institutional, behavioral and psychological aspects. This paper investigates those four representative sub-cultural levels: campus culture, material culture, behavioral culture and Chinese traditional culture, and intends to find out those key problems affecting their cultural adaptability and offer some possible solutions. Our subjects are foreign students from 3 universities in Chongqing university town, and we hope to provide them some advice to live and study happily in Chongqing.

\section{RESEARCH DESIGN}

(1) Research time and respondents: this study was carried out by our research team in the middle of September, 2017.

\footnotetext{
* Funded by 2017 Chongqing Postgraduate Innovation Program (No. CYS17191), supervised by Prof. Xianyou Wu.
} 
Research members were divided into three groups to hand out the questionnaires to foreign students in three universities including Chongqing University, Chongqing Medical University and Chongqing Normal University.

(2) Research objectives and significance: this survey aims at finding out some existing problems, analyzing those practical reasons that may influence the intercultural adaptability, and providing some relevant solutions.

(3) Research methods: documentation method, survey research and statistical analysis.

(4) Research questions and contents: this questionnaire involves such aspects as Chinese professional knowledge, individual lifestyle, emotional attitude, etc. It covers four dimensions including campus adaptation, material cultural adaptation, behavioral adaptation and Chinese traditional adaption. This questionnaire consists of seven multiple choices and twenty-eight one-choice questions.

\section{DATA COLLECTION AND ANALYSIS}

In order to ensure the reliability and validity of this study, research team went to Chongqing University, Chongqing Medical University and Chongqing Normal University to conduct the field investigation. And the research team handed out 300 pieces of questionnaires and got back 295 responses. During the whole process, research members were all the time on the scene. From the questionnaires handed out and got back, research members made a statistic analysis and calculated that the validity is up to $98.3 \%$. Meanwhile, the group members had some face-to-face interviewees with some subjects and got the first-hand data of foreign students' intercultural adaptation.

\section{A. Campus Cultural Adaptation}

Campus culture is part of the overall cultural performance of students' learning environment and educational philosophy. As Li (2016) put forward, "it takes campus as the main space, extracurricular cultural activities as the main contents, and campus spirit as the main feature. Meanwhile, it has some effects on thinking and intercultural adaptation of foreign students" (Li Yue, etal, 2016, p.191-196). Hence, cultivating a good awareness of campus culture is the fundamental requirement for foreign students. Based on the concrete contents of campus adaptation, 10 questions are designed for this part, including three aspects: personal information, teaching and learning styles and practical factors. For personal information, 2 questions are asked, such as learning status, self-appraisal of language level; for teaching and learning styles, 4 questions are asked, such as teaching methods, teaching devices, current textbooks, after-class activities, learning atmosphere; for practical factors, 4 questions are asked, such as social contact, language practicing activities, part-time job, internship. The following figure will show foreign students' Chinese level.

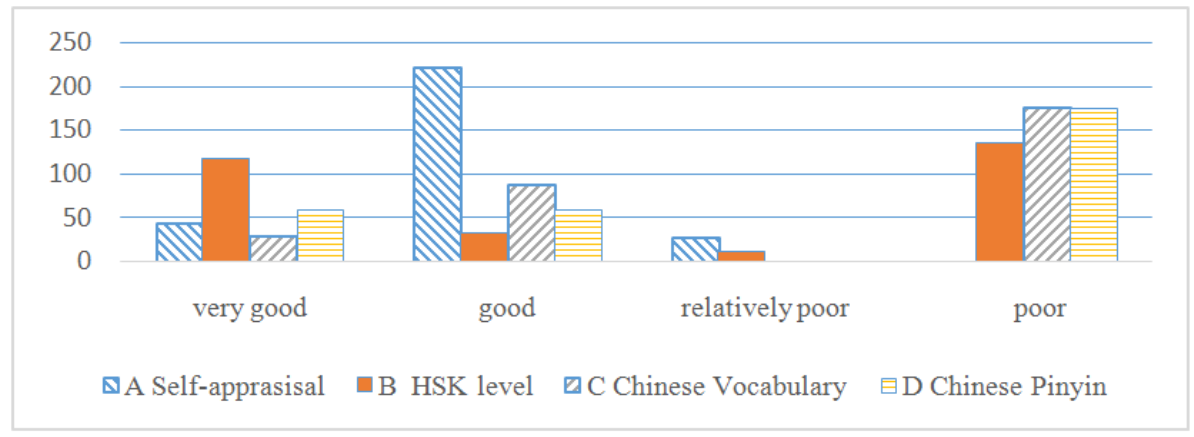

Figure 1 Language level

The figure shows that most of foreign students are content with their textbooks, after-class activities and learning atmosphere. They are also satisfied with teaching methods, such as heuristic teaching method, researching and discussion teaching method, problem-oriented teaching method. Besides, they prefer some new teaching devices, such as mooc, micro-class and flipped class. Xie (2015) said, "compared with traditional classrooms, the unique advantages of moocs, flipping classrooms, micro lessons, and micro-videos are flexible, autonomous, repeatable, brief, themes-oriented, and interactive." (Xie Guilan, 2015, p.43-46). Due to the introduction of Western teaching ideas and models, many Chinese teachers have made relevant improvements. The acceptance of foreign students for teaching methods is the result of such efforts.

It also shows that most foreign students have acquired language knowledge well, especially Chinese grammar and Pinyin. As shown in Figure 1, 40\% foreign students have a good acquirement of Chinese grammar (10\% very good $+30 \%$ good), and $40.6 \%$ foreign student's Chinese Pinyin level is high $(20.3 \%$ very high $+20.3 \%$ high). Basic knowledge of written aspects enables most foreign students to pass the HSK examination easily. However, $50 \%$ foreign students $(4 \%+46 \%)$ are not quite satisfied with their language level. The reasons are that different learning programs for foreign students may result in their different Chinese levels. Generally speaking, the longer they stayed, the better. Also, there are different expectations for foreign students to study in China. Some of them set the goal of working in China or engaging in some related work, others may return home. Most of all, the lack of related language speaking practice is 
one of the reasons for their low self-appraisal of practical language.

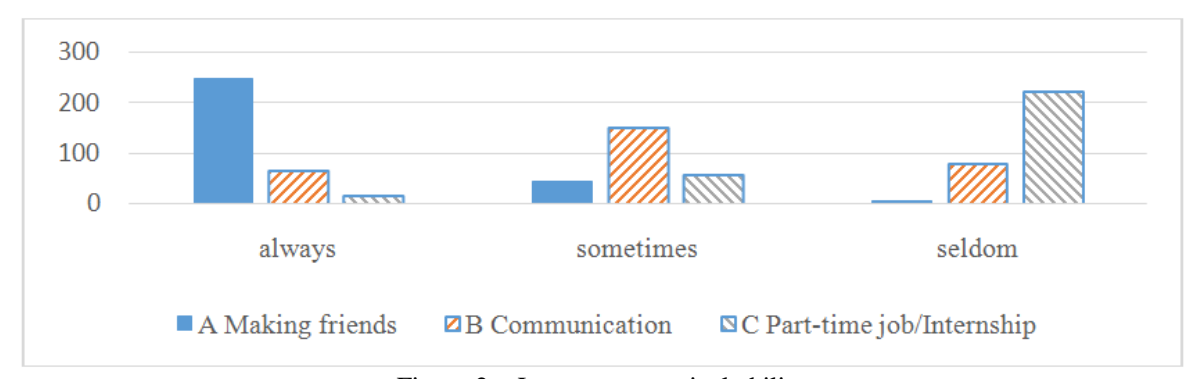

Figure 2 Language practical ability

The figure 2 shows that $83.7 \%$ foreign students are willing to make friends with Chinese students and only 5\% foreign students always do part-time job or internship. There is a big contradictory between communication and internship. Liu (2017) thinks that different types of after-class activities are helpful for foreign students to assimilate Chinese culture. Those activities can expand their global views. (Liu Ruonan, 2017, p.120-121). As we know, after-class activities of different types and ways are beneficial for foreign students to overcome difficulties and enrich their life experience and cultural awareness. These after-class activities are also the fundamental factors for foreign students to adapt campus culture better. From this perspective, this current phenomenon is not perfect.

\section{B. Material Cultural Adaption}

Material culture refers to a totality of material production activities and its product, and it is also the tangible and humanized object, which covers the basic needs of human beings, such as clothing, food, housing and transportation. The figure shows that most foreign students have a good impression of Chongqing, such as mountainous city, foggy city and international metropolitan. However, some of them are not clear about Sichuan dialect. Besides, $80 \%$ and $85 \%$ foreign students are satisfied with transportation in Chongqing and natural environment of university. Nevertheless, more than $71.37 \%$ foreign students could not recognize the architectural style of Xijie (Chongqing university town). Hence, grasping a good understanding of material culture, such as dialect, architectural style, transportation system and famous scenic spots, etc. is one of the key parts to intercultural adaptation for foreign students. For material culture adaptation, 10 questions are designed in the questionnaire, from question 11 to question 20.

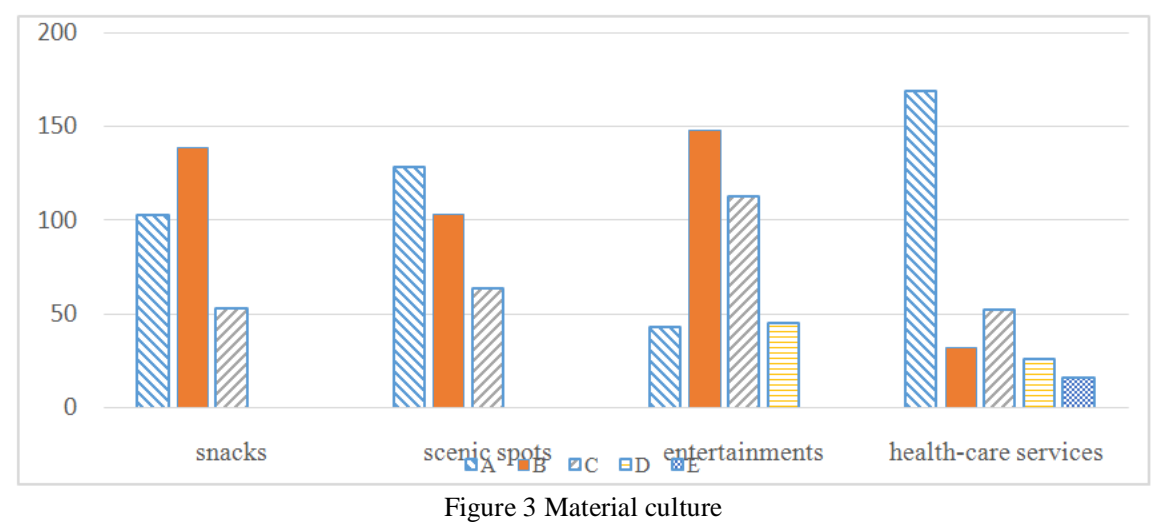

Traditional food, scenic spots and entertainments are the carriers of the material culture. Hence, foreign students are eager to try different kinds of local traditional food and love to visit more scenic spots and entertainments. As Hu (2008) puts forward, "Dietary culture belongs to material culture, because food is tangible and can meet the basic demand of human beings. Food contains the cultural value and technology from manufactures" (Hu, 2008, p.73-75). While foreign students are insufficient in this perspective. The figure 3 shows that $44.56 \%$ foreign students like to eat 4 to 6 kinds of local snacks, only $20.65 \%$ of them have eaten almost all kinds of local snacks. With respect to local tourist attractions, local entertainments and local health-care services, $21.73 \%$ of them have visited local tourist attractions, $70.6 \%$ of the students have not taken part in playing Majiang (a game which is popular in China) and square dance yet, $95 \%$ of the students have not experienced scraping therapy (traditional Chinese therapy), etc. This situation is closely related to the present of paying little attention to material culture in the long term.

\section{Behavioral Cultural Adaption}

Behavioral Cultural adaption means that a person gets well along with his or her surroundings. It relates to daily skills or tasks and reflects an individual's social and practical competence to meet the demands of everyday living. At the same time, behavioral cultural adaption changes in personal values, and the expectation of others. 


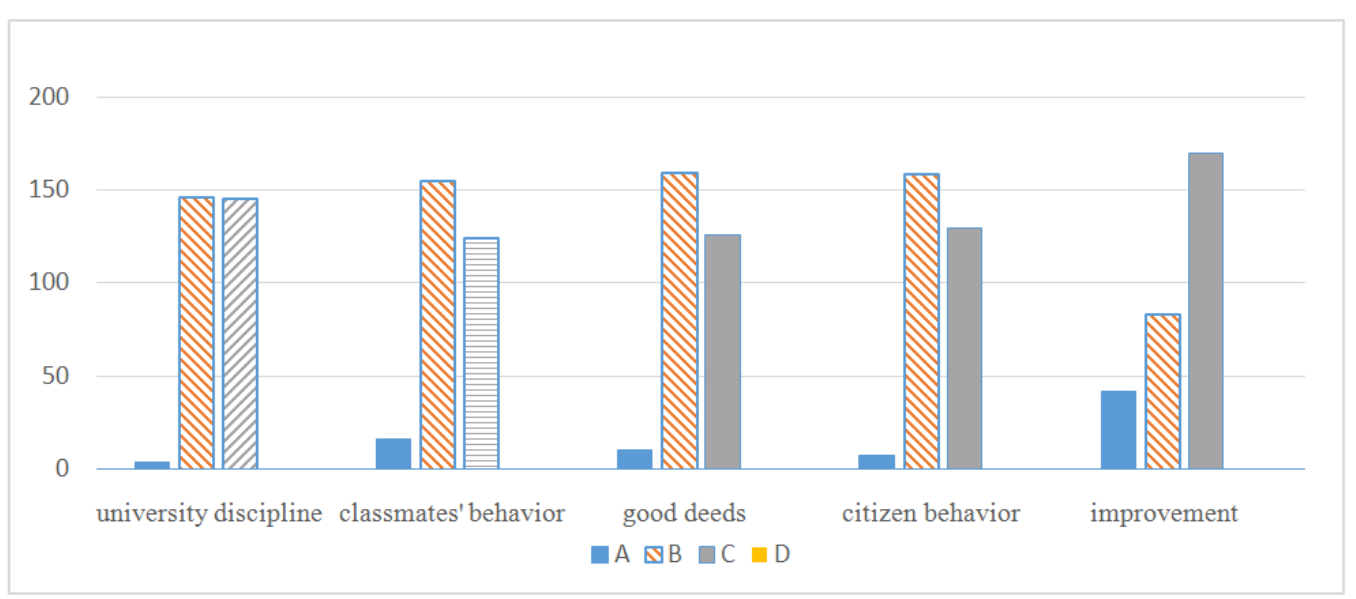

Figure 4 Behavioral Culture

The figure 4 shows that most foreign students choose light rail as travel tools and this is due to the geographic environment of Chongqing (a mountainous city); foreign students are willing to learn to use chopsticks when having traditional Chinese meals and observe university rules. However, the figure also shows that $70 \%$ foreign students believe local citizens' behavior and standard Chinese still need to be improved. Chen (1998) explains, compared with Western countries' communication tradition, the communication of Chinese still maintains a strongly rural feature, which big differences exist in interpersonal relationship. And culture, personal characteristics and experiences are influencing factors in behavioral aspects of interpersonal relationship. That is to say, if you are not their close relatives or friends, you may have some difficulties in chatting with them.

\section{Chinese Traditional Adaption}

Traditional culture refers to cultural customs involving such aspects as arts, values, literature, thinking style, aesthetic preference, social psychology and ideology. Zhang (2004) believes that Chinese traditional culture is the mirror of daily life thinking, spirit, popular psychology, individual demands and emotions. It is necessary to know about Chinese culture if you want to get a better understanding of China. Therefore, acquiring a good understanding of traditional culture is crucial to intercultural adaptation for foreign students.

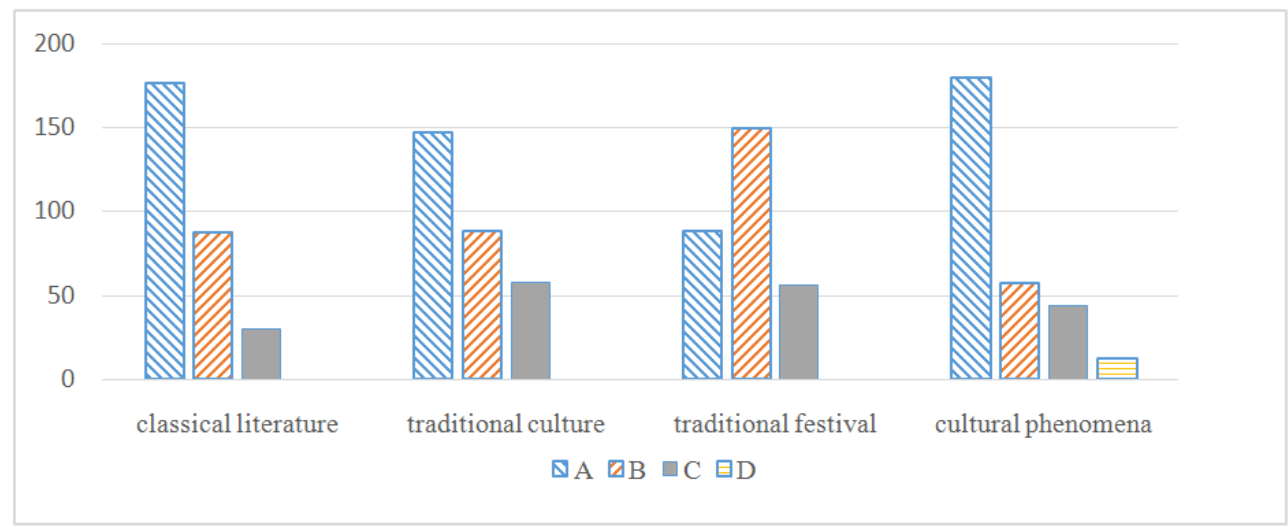

Figure 5 Chinese traditional culture

The figure 5 describes some typical cultural issues, including Chinese classical literature, Chinese traditional culture, Chinese traditional festival and Chinese cultural phenomena. The four parts contain the essence of Chinese traditional culture. Their characters, languages, allusions and themes are the main sources of Chinese thinking and expressions. As for Chinese classical literature, four great classical novels of Chinese literature play an vital role and represent the best achievements of Chinese classical novels. Take Journey to the West as examples as example, Journey to the West describes the features of Chinese thinking, transcends religious theology and corrects the prejudice that some Westerners' view that Chinese people do not have religious beliefs. However, the figure shows that nearly $60 \%$ students know little about four great classical novels of Chinese literature.

Besides, Chinese traditional culture is the priceless treasure of China and it shapes people's life in many ways. However, with respect to Chinese traditional festivals, only $20 \%$ foreign students have attended 8-11 kinds of local traditional festivals, 50\% foreign students do not have any knowledge of Chongqing local culture, such as Chuanjiang Haozi (a typical song for boat trackers along the Yangtze River), Longmen Zhen (folk tales), etc. Only 5\% of them have known more than four kinds of Chongqing local culture. It is obvious that foreign students' understanding of Chinese traditional culture and Chongqing local culture is inadequate. 


\section{E. Some Major Problems}

Through the analysis above, we find the following problems of foreign students' intercultural adaption in three universities':

(1) Some foreign students do not have sufficient Chinese competence. There are 5 questions related to their Chinese competence, including language level and practical activities, but the results are not satisfactory. Only 15 foreign students often get in touch with Chongqing local people and try to talk with them in Chinese.

(2) Some foreign students are unfamiliar with Chinese material culture, including dialect, architectural style and famous scenic spots. Question no. twelve, thirteen, eighteen are about foreign students' understanding of material culture. The data shows most of them cannot recognize the dialect of Chongqing and the architecture style of Xijie. And more than 240 foreign students have not visited some typical scenic spots in Chongqing.

(3) Some foreign students are insensitive to Chongqing's behavioral culture. Question no. 28 is about foreign students' personal opinions of Chongqing citizens' behavioral culture including etiquette, behavior and dialect. Most of them think local people need to improve their standard Chinese.

(4) A number of foreign students are not familiar with Chinese traditional and local culture. Questions no. thirty-two, thirty-three and thirty-five are related to Chinese traditional culture, such as four great classical novels of Chinese literature. As for Chinese traditional culture, which contain martial arts, paper-cutting, and so on, and the local cultural phenomena include Chuanjing Haozi (a traditional folk singing form sung by boatmen from Chongqing and Sichuan), Longmen Zhen (folk tale in Chongqing and Sichuan), etc. from this survey we find they are lack of Chinese cultural knowledge.

\section{F. Some Possible Solutions}

According to the previous problems, some relevant solutions are given as follows:

(1) Implement the same management to foreign students as Chinese. To make sure that foreign students have a sufficient Chinese competence, the host university should implement the same management of foreign students as Chinese. Intercultural communication as a dynamic process emphasizes the participation of both the local students and the foreign students, so that they may have more mutual interactions. And at the very beginning, language learning is the primary concern for foreign students to deal with, but because there are different management rules for foreign students, they usually do not have a real Chinese language environment to practice their oral Chinese. Therefore, it is necessary for the foreign affairs department to conduct the same management plans for them. They can provide some classes that foreign students and Chinese students can study together so as to create more chances for foreign students to practice their Chinese. Most importantly, foreign students can communicate with local students, like learning issues, language practicing, part-time job or internship, etc. to get more supports form different aspects. And it would be beneficial for foreign students to cultivate a better campus cultural adaption.

(2) Strengthen social supports. A good social support network is considered to be helpful to alleviate the pressure of life, keep in good health and achieve the sense of happiness (He, 2001). And the social network is a relatively stable relationship that individuals can obtain various supports, such as the supports of finance, affection and emotion, etc. With help of social support, people could solve some problems more easily in their daily life. Before coming to Chongqing, the foreign students nearly know nothing about the history, culture and social system of this city. And nearly all of their knowledge about Chongqing is based on their imagination. Besides, there are three types of interpersonal relationships of foreign students. First, many foreign students keep the single cultural interpersonal relationship, which they only communicate with their domestic compatriots to get some emotional supports; Second, some foreign students choose to keep in touch with some local students and staffs coming from host country to get some more professional and academic assistance; Third, only a small part of foreign students can get along well with local people including Chinese students, staffs, teachers and other citizens at the same time. The three types of interpersonal relationships play different roles in the adaptation process of foreign students and provide different types of social supports. Among all of these three kinds of interpersonal relationships, the first two are not the best choice. Because foreign students cannot contact with more people. Only the last type of interpersonal relationship reveals a better way for foreign students to feel leisure and entertainment of local environment. It is the most effective for foreign students to adapt intercultural distances. During this time, foreign students may get along with more local people in different situations naturally. In view of this situation, Chinese universities should provide various activities and programs for foreign students to enable them have more opportunities to enjoy the exotic flavor of Chongqing. For instance, Chinese university students can make some group tours and lead foreign students to visit some local famous scenic spots, enjoy a variety of flavor special snacks, and experience some local entertainments so as to stimulate their interest of this city and let them feel the friendliness of Chinese.

(3) Strengthen the communication with foreign students. The Chinese university should establish sufficient exchange platform and system, strengthen the communication and interaction, and regard it as a main part of daily work, which would enhance students' mutual understanding, eliminate misunderstanding, exchange information and discover problems timely, and all of this would be beneficial for foreign students' intercultural adaptation. Chen (1998) finds that Chinese people emphasize the closeness and distance of relationship, and comply with the principle of internal and external differences in interpersonal relationship. Meanwhile, Chongqing is a city where the dialect is more common 
than Mandarin in daily communication and citizens' behaviors are more obvious than other regions. Thus, one of the most important thing during the process of intercultural adaptation is that the Chinese universities must ensure the promptness and effectiveness of the information. If foreign students want to know the local culture, they need sufficient information, which is also the premise for foreign students to integrate into the local society. Without the exchange of information, foreign students are prevented from entering into the local society, which would make them have the sense of alienation. Therefore, the managers should inform them the local important events in an efficient way.

(4) Foster foreign students' consciousness of Chinese traditional culture. A great number of foreign students know little about Chinese traditional culture, which makes intercultural adaptation difficult. In consideration of this, Chinese university should provide some relevant cultural lectures, such as four great classical novels of Chinese literature and carry out some cultural activities, such as 'the Reader', 'Chinese Poetry Conference' ect, which can give foreign students more exposure to the Chinese language environment. Meanwhile, let foreign students take part in some Chinese traditional festivals would be an effective way for them to contact with Chinese traditional culture. They can celebrate some typical festivals with local residents, play interesting games, such as playing riddle games on Lantern Festival, making zongzi on Dragon Boat Festival, writing couplets on Spring Festival, etc, all of these activities are more interesting than learning in classroom, which would arouse foreign students' interest to know more about Chinese traditional culture as well.

\section{CONCLUSION}

This paper makes a survey of the foreign students in three universities located in Chongqing university town, from four aspects, like campus cultural adaptation, material cultural adaptation, behavioral cultural adaptation and Chinese traditional adaptation, discovering that some foreign students are not adaptable to campus culture, because they lack the practical ability of language, and during the learning and living process, they tend to live in their narrow social groups and ignore the importance of Chinese local culture, meanwhile, most of them are not adaptable to dialect and behavior... As for problems discussed above, this paper tries to offer some suggestions: for example, implement the same management to foreign students as Chinese by arranging foreign students and Chinese students into the same class, setting up some meaningful activities for foreign students to communicate with Chinese students to inspire their curiosity of campus culture; strengthen the social support by offering the website to provide enough information of Chongqing and relating universities and organizing some group tours, such as local famous scenic spots to stimulate their interest for Chongqing material culture; strengthen the communication with foreign students by establishing sufficient exchange platform and system for foreign students and informing foreign students the local important events in an efficient way; Foster foreign students' consciousness of Chinese traditional culture by making Chinese traditional culture lectures, carrying out some activities, such as the Reader, Chinese Poetry Conference and so on and organizing activities on important festivals and setting up courses about Chinese traditional culture for foreign students to choose to stimulate their interests and narrow the cultural gap.

\section{REFERENCES}

[1] Chen Hui. (2003). The Research in Behavioral Psychology of Foreign Students' Sociocultural Adaptation in China. Journal of Beijing Normal University (Social Science Edition), Vol. 06: 135-142.

[2] Chen Xiangming. (1998). The Sojourner and Foreigner: Intercultural Interpersonal Communication of International Middle School Students. Changsha: Hunan Education Press.

[3] Cheng Yuzhen. (2009). Outline of Chinese Culture. Beijing: Foreign Language Teaching and Research Press.

[4] He Zhaiping. (2001). Literature Reviews of Social Support Network, Social Science Abroad, Vol. 01:76-82.

[5] Hu Minzhong. (2008) On Material Culture and Non-material Culture. Expanding Horizons, Vol. 08:73-75

[6] Lu Jie. (1990). Sociology of Education. Beijing: People's Publishing House.

[7] Li Yue, Zhao Yinxin, Yang Minglei. (2016). Appliance Researches on Campus Culture's Contribution to Intercultural Adaptation. Medical Education Management, Vol. 2:191-196.

[8] Liu Ruonan. (2017). The Role of Campus Cultural Activities in Constructing the Platform of Intercultural Communicative Competence and Its Implementation. Heilongjiang Science, Vol. 8: 120-121.

[9] Ward, C. \& Searle, W. (1991). The Impact of Value Discrepancies and Culture Identity on Psychological and Sociocultural Adjustment of Sojourners. International Journal of Intercultural Relations, Vol. 15:209-224.

[10] Xie Guilan. (2015). Analysis of Five Relationships Between Moocs, Flipped Classroom, Micro-lecture and Micro-video. Education Science, Vol. 31:43-46.

[11] Yang Junhong. (2009). Cross-Cultural Adaptation among International Students in P.R.C. Institutions of Higher Education. Shanghai: Shanghai Academy of Social Science Press.

[12] Zhang Dainian, Fang Keli. (2004). Introduction to Chinese Traditional Culture. Beijing: Beijing Normal University Press.

Siqi Ye was born in Chongqing, China. She is currently an MA candidate specializing in literary stylistics at the College of Foreign Languages and Literatures, Chongqing Normal University, China. Her interests cover literary stylistics and functional stylistics. 
Haijiao Xue was born in Hubei, China. He is currently an MA candidate specializing in English Literary Studies at the College of Foreign Languages and Literatures, Chongqing Normal University, China. His interests cover Western literary theories and the 18th century English classical novels.

Yanling Zheng was born in Yunnan, China. She is currently an MA candidate specializing in literary stylistics at the College of Foreign Languages and Literatures, Chongqing Normal University, China. Her interests cover literary stylistics and language teaching. 